\title{
RESPONSABILIDADE E CULPA ALEMÃ: UM DIÁLOGO ENTRE HANNAH ARENDT E KARL JASPERS
}

Fabiano Tizzo*

Resumo: O artigo pretende analisar e problematizar a ideia de "responsabilidade" debatida por Hannah Arendt (1906-1975) e a perspectiva de "culpa alemã" pensada por Karl Jaspers (18831969). Ambos os autores, após a $2^{\mathrm{a}}$ Guerra Mundial, confrontam a Alemanha com um passado de crimes dantescos. Portanto, para Hannah Arendt, atribuir a responsabilidade individual aos sujeitos do nazismo era inarredável, para que houvesse pessoalidade proporcional aos feitos praticados por cada indivíduo que colaborou com o regime hitlerista. Para Karl Jaspers, a questão da culpa alemã é que deveria ser considerada e debatida com o intuito de compreender a Alemanha após o nazismo e assim traçar novos rumos ao país, inclusive ao longo dos julgamentos de Nuremberg, em que uma grande enxurrada de acusações e culpa se intensificou e recaiu sobre o povo alemão com base no suposto apoio a Hitler.

Palavras-chave: culpa, responsabilidade, moral, nazismo, Alemanha.

\begin{abstract}
This article aims to analyze and discuss the idea of "responsibility" discussed by Hannah Arendt (1906-1975) and the prospect of "German guilt" thought by Karl Jaspers (1883-1969). Both authors, after the 2nd World War, confront Germany with a history of enormous crimes. So, to Hannah Arendt, assign individual responsibility to the subjects of Nazism was unswerving, so that there was proportional to personhood made practiced by every individual who collaborated with Hitler's regime. Karl Jaspers, the question of German guilt is that should be considered and discussed in order to understand Germany after Nazism and thus set new directions for the country, including over the Nuremberg trials, in which a large flood of accusations and guilt intensified and fell on the German people based on the alleged support to Hitler.
\end{abstract}

Keywords: guilt, responsibility, moral, Nazism, Germany.

\section{Introdução}

* Mestre e especialista em História pela PUC-SP. Especialista em Política e Relações Internacionais pela FESPSP e Bacharel em Sociologia e Política pela mesma instituição. Possui graduação em História pelo UNIFAI e especialização em Arqueologia pela UNISA. Atua como professor no curso de História da Universidade de Santo Amaro e nos cursos de Serviço Social e Direito da Faculdade Tijucussu. 
Nesta introdução elencamos algumas das características dos autores que compõem nosso tema, e faremos alguns apontamentos iniciais da trajetória de Hannah Arendt e, mais adiante, sobre Karl Jaspers, para situar o leitor sobre as principais características dos autores e sua relação com o tema deste artigo.

Hannah Arendt é uma renomada intelectual judia que escreveu durante e após o nazismo. Além das motivações pessoais para escrever sobre o tema, ela foi impulsionada pelos fatos que vieram à tona no pós-guerra, tais como o advento dos campos de concentração, que ela conheceu de perto, e cuja estrutura de funcionamento e ideologia foi objeto de sua criteriosa atenção. Arendt tornou-se uma referência ao publicar Origens do Totalitarismo (1951) - "momento em que se destacou no cenário intelectual norte-americano, europeu e depois mundial"2. Após este lançamento, obteve a cidadania norte-americana quando já lecionava em universidades como a New School e a Universidade de Chicago. Posteriormente publicou A Condição Humana (1958), em que faz uma reflexão profunda sobre a modernidade, e, por fim, Eichmann em Jerusalém: Um relato sobre a banalidade do mal (1963). Nesta última obra a autora cunha a expressão "banalidade do mal", ao acompanhar o complexo e polêmico julgamento de um burocrata nazista. O livro faz inúmeras reflexões sobre o caso e a figura do sujeito Eichmann, problematizando as questões morais, a responsabilidade pessoal e legal do réu quanto aos crimes dantescos de que era acusado. Assim, a partir destas e outras obras toda sua potencialidade intelectual passa a ser admirada nos meios acadêmicos de seu tempo e justifica a sua relevância para este artigo.

Ainda sobre a autora, convém ressaltar que foi presa em 1933 na Alemanha devido à perseguição que havia contra os judeus durante os anos trinta. Permaneceu presa por oito dias, acusada de envolvimento com o sionismo ${ }^{3}$, principalmente depois que foi incumbida pelos sionistas, em 1933, de reunir uma coletânea de materiais que evidenciavam a ampla ação antissemita em instituições da sociedade civil alemã. Ela só foi libertada devido à amizade que fez com o policial que a prendeu em Berlim: "Tive muita sorte" ${ }^{4}$, comentou Arendt mais tarde. Eram tempos difíceis para todos os judeus da Alemanha, inclusive para ela. Percebendo que a Alemanha passava por intensas mudanças, Arendt tratou de deixá-la de modo ilegal e clandestino (sem

\footnotetext{
${ }^{2}$ CORREIA, Adriano. Hannah Arendt. Rio de Janeiro: Jorge Zahar Editora, 2007, p. 38.

${ }^{3}$ Foi um movimento criado pelo judeu austríaco Theodor Herzl (1860-1904) que pregava a reivindicação de um território com vista à implantação de um Estado judaico, onde todo o povo judeu pudesse se estabelecer. Foi iniciado no século XIX e o seu nome deriva de Sion, uma das colinas de Jerusalém. Mais tarde, em 1948, uma das principais aspirações do sionismo foi atendida, ocorreu a fundação do Estado de Israel. Antes da criação do estado israelense, houve o apoio da Inglaterra em 1917 com a Declaração de Balfour; depois, em 1922, com a Liga das Nações. AZEVEDO, Antônio Carlos do Amaral. Dicionário de nomes, termos e conceitos históricos. Rio de Janeiro: Nova Fronteira, 1999 , p. 419.
}

${ }^{4}$ ARENDT, Hannah. A dignidade da política. Rio de Janeiro: Relume Dumará, 2003, p. 127. 
documentos), pois o processo oriundo de sua prisão seguiu adiante. Passou a viver na França, onde permaneceu até 1940, quando os nazistas ocuparam o país; e encontrou refúgio nos Estados Unidos.

Sobre Karl Jaspers, foi professor de Hannah Arendt ao longo dos anos vinte na Alemanha, sendo que ambos - cada um ao seu modo - vivenciaram o processo de ascensão e queda do $3^{\circ}$ Reich $^{5}$. Jaspers vivia na Alemanha e também observou de perto a ideologia nazista. Em 1937 foi afastado do cargo de professor na Universidade de Heidelberg e em 1945 quase foi enviado para um campo de concentração, por ser casado com uma judia. Somente em 1945-6 é que Jaspers retoma suas atividades na academia, e, em 1948, se transfere para a Universidade da Basiléia (Suíça). Nos anos de 1945-46, ele ministrou um curso sobre a questão da culpa e a responsabilidade política da Alemanha. Alguns meses depois, seus apontamentos desse curso foram organizados e publicados, dando origem ao livro intitulado O problema da culpa (Die Schuldfrage), que será objeto de análise deste artigo, afinal Jaspers foi capaz de "intervir diretamente nas questões políticas de sua atualidade" ${ }^{\circ}$, como afirmou Arendt. O autor também foi responsável pela publicação de outras obras relevantes que discutem com profundidade as questões políticas de seu tempo, como: O homem na Idade Moderna (1933) e A bomba atômica e o futuro do homem (1958).

Por fim, Jaspers afirma que "estamos no mundo, mas nunca temos como objeto a totalidade

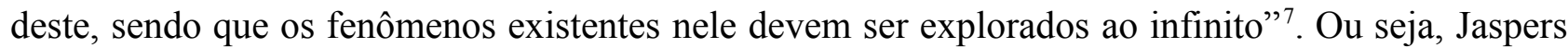
e Arendt esforçaram-se ao máximo para compreender a totalidade do fenômeno nazista em seu tempo, daí a relevância de ambos como referências para se pensar a temática ora apresentada.

\section{Sobre a culpa e responsabilidade}

De acordo com o historiador Kitchen, "o horror, o genocídio e a esqualidez da moral praticados pelos alemães durante a $2^{\mathrm{a}}$ Guerra Mundial retiraram da Alemanha o status de grande

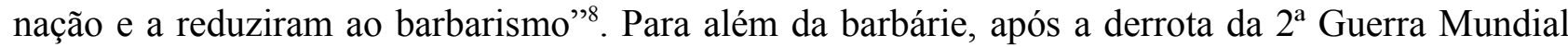
pelos Aliados", ela "ficou ainda mais enfraquecida pelo peso da culpa que veio a seguir"10.

\footnotetext{
${ }^{5}$ Literalmente, significa império. Em síntese, o $1^{\circ}$ Reich teve seu auge no século X, durante o Sacro Império Romano Germânico e iniciado no Império Carolíngio; $\mathrm{O} 2^{\circ}$ Reich foi pensado ao longo da era Bismarck no século XIX, oriundo do desejo de unificar os 37 reinos da Alemanha em uma só nação, o que ocorreu em 1871; E sobre o $3^{\circ}$ Reich, o termo foi utilizado por Hitler e incorporado ao nazismo após a tomada do poder em 1933 com pretensões políticas e pautado na tradição imperial alemã. Não foi mais utilizado após a derrota do país na $2^{\mathrm{a}}$ Guerra Mundial. AZEVEDO, Antônio Carlos do Amaral. Dicionário de nomes, termos e conceitos históricos. Rio de Janeiro: Nova Fronteira, 1999, p. 386.

${ }^{6}$ ARENDT, Hannah. Homens em tempos sombrios. São Paulo: Companhia das Letras, 2010, p. 83.

${ }^{7}$ JASPERS, Karl. Introdução ao pensamento filosófico. São Paulo: Cultrix, 2005, p. 23.

${ }^{8}$ KITCHEN, Martin. História da Alemanha Moderna: de 1800 aos dias de hoje. São Paulo: Cultrix, 2013 , p. 430.

${ }^{9}$ Os países aliados que lutaram contra a Alemanha nazista são: Inglaterra, Estados Unidos, União Soviética e França.

${ }^{10}$ KITCHEN, op. cit., p. 430.
} 
Segundo Bankier, após a derrota da Alemanha na $2^{\text {a }}$ Guerra Mundial, "muitos alemães procuraram fugir da consciência do genocídio e tentaram manter-se o mais ignorantes possível, pois o conhecimento gera culpa, uma vez que implica responsabilidade" ${ }^{11}$.É no tocante à responsabilidade dos sujeitos históricos envolvidos que Hannah Arendt se mostra expressiva nesta análise. Ela levanta a discussão sobre todo o impacto causado pela $2^{\mathrm{a}}$ Guerra Mundial oriundo da ideologia totalitária, bem como sobre a responsabilidade de cada indivíduo que atuou em favor do nazismo. Para a autora, cada um dos indivíduos que praticaram crimes no período nazista deveria ter sido responsabilizado individualmente, e não o Estado alemão; ainda que eles estivessem cumprindo ordens do Estado, visto pela comunidade internacional como sendo um Estado de direito, ainda assim os autores "deveriam ser responsabilizados por suas ações" 12 individualmente. Portanto, a caracterização dos sujeitos históricos (indivíduos) como perpetradores é necessária para Arendt, do contrário, esse tipo de impasse poderia tornar inoperantes os processos de acusação contra os autores, segundo se depreende da citação abaixo:

[...] na sala de um tribunal não se deve julgar um sistema, uma história, ou uma tendência histórica, um ismo, o antissemitismo, por exemplo, mas uma pessoa, e se o réu é por acaso um funcionário, ele é acusado precisamente porque até um funcionário ainda é um ser humano, e é nessa qualidade que ele é julgado (ARENDT, 2004, p.92).

Para Jaspers, a Alemanha “não poderia virar a página sobre o período do Partido Nacional Socialista (nazista) como se fecha um parêntese; se ela quisesse renascer, deveria admitir as consequências de seus erros passados" (DELACAMPAGNE, 1997, p. 168). Para o autor, era necessário que os alemães iniciassem um intenso debate a partir da questão da culpa pelo nazismo com todos os seus desdobramentos. Ele ousou debater e encarar a situação alemã, em face do caos gerado pela derrota na $2^{\text {a }}$ Guerra e convidou os demais a enfrentar o problema da culpa, que deveria ser entendida nos sentidos criminal, político, moral e metafísico, conforme se depreende nas passagens adiante:

1) Sobre a culpa criminal,"são culpados os indivíduos que cometeram atos que se enquadram na categoria de crimes no âmbito do sistema jurídico""13;

\footnotetext{
${ }^{11}$ FRIEDLÄNDER, Saul. A Wehrmacht, a sociedade alemã e o conhecimento do extermínio em massa dos judeus. In: Crimes de guerra: culpa e negação no século XX. Rio de Janeiro: Editora Difel, 2005, p. 62.

${ }^{12}$ LAFER, Celso. Reflexões sobre a atualidade da análise de Hannah Arendt sobre o processo Eichmann. In depois. Curitiba: Editora UFPR, 2013, p. 26-27.

${ }^{13}$ JASPERS, Karl. El problema de la culpa: sobre la responsabilidad política de Alemania. Barcelona: Ediciones Paidós, 1998, pp. 88 a 89. (Obs: resumo e tradução nossa.)
} 
2) Quanto à culpa política, “os cidadãos de um Estado em que o governo é proveniente de eleições democráticas - como era a Alemanha antes de Hitler - são corresponsáveis pelos atos, assim como os crimes cometidos por esse Estado"14;

3) Referente à culpa moral, "cada testemunha dessa tragédia deve se questionar se ela fez, diante das duras condições em que se encontrava, o melhor que podia"15;

4) Por fim, no que se refere à culpa metafísica, esta "do ponto de vista da solidariedade universal cada um de nós ainda que nada se possa fazer - não podemos ignorar o fato de que outros homens sejam maltratados, mesmo que isso ocorra em outros países"16.

Os quatro tipos de culpa elaborados por Jaspers "consistem em, primeiramente, distinguir as suas naturezas, instâncias julgadoras e consequências" ${ }^{17}$, como afirmou Medeiros. Para Jaspers, a culpa não deveria ser aplicada ao coletivo, ou seja, a todo o povo alemão. O autor expõe que os atos cruéis e injustos foram cometidos por homens comuns e normais. Portanto, ainda que todos os alemães admitissem em tese uma culpa coletiva, esta seria insuficiente, pois seria diluída na sociedade e não haveria a pessoalidade ou a materialização necessária para que a responsabilidade individual fosse devidamente atribuída. A generalização da culpa seria uma forma de desviar-se do problema - e não de enfrentá-lo. Já o enfrentamento dela (culpa) seria um chamado à reflexão e supostamente a uma reconciliação dos alemães com o mundo, afinal eram parte da humanidade e jamais poderiam deixar de sê-lo - apesar das atrocidades cometidas - daí a necessidade de assumir os feitos organizados pelo nazismo, pois, no entender de Jaspers:

\begin{abstract}
Nós, os alemães, temos o dever, sem exceção, de encarar o problema de nossa culpa e de tirar as consequências disso. Nossa dignidade humana nos obriga a isso [...] nossa própria vida [...] só poderá ser digna se formos sinceros com nós mesmos. Os outros levantam a questão de nossa culpa, mas, mais do que isso, é uma questão que nós próprios nos fazemos. A resposta que dermos a ela em nosso íntimo fundamentará nossa consciência atual do ser e de nós mesmos. É uma questão vital para a alma alemã (JASPERS, 1998, p. 44-51).
\end{abstract}

Impunha-se, portanto, ao povo alemão encarar a realidade e enfrentar a culpa que lhe atribuíam. Segundo autor, "se os alemães encarassem e refletissem sobre sua culpa, supostamente poderia ocorrer uma mudança profunda ou renovação da essência alemã” (JASPERS, 1998, p. 51), vista como necessária. A partir do momento em que a sociedade alemã passasse a questionar seus

\footnotetext{
${ }^{14}$ Idem, pp. 79 a 81.

${ }^{15}$ Idem, pp. 81 a 88 .

${ }^{16}$ Idem, pp. 88 e 89.

17 MEDEIROS, Débora Araújo. Tempos sombrios: Karl Jaspers e a culpa alemã. Disponível em: $<$ http://periodicos.unb.br/index.php/polemos/article/view/7240/6442> Acesso em: 22 dez. 2014, p. 03. 
próprios feitos, ela faria um bem a si mesmo, pois "questionar-se seria uma forma de se libertar do peso de sua consciência" (JASPERS, 1998, p. 44), comenta o autor.

É importante lembrar que, após a rendição da Alemanha na $2^{\mathrm{a}}$ Guerra Mundial, em 07 de maio 1945, grande parte dos alemães é vista como culpada pelo suposto apoio ao Führer, haja vista que os julgamentos de Nuremberg contribuíram e fortaleceram o discurso sobre uma suposta culpa alemã ao propagar o ocorrido nos campos de concentração. Antes mesmo de terminada a $2^{\text {a }}$ Guerra Mundial, os países Aliados que lutaram contra o nazismo já discutiam, em encontros e conferências, a possibilidade de julgar os principais líderes alemães e suas instituições após vencê-los. Assim, os vencedores instituíram o histórico "Tribunal de Nuremberg"18 (1945-1949), este que, além de evidenciar e tornar público os crimes de guerra, atribuiu a ex-nazistas indiciados a responsabilidade individual no âmbito da justiça para que respondessem como réus.

Para Bazelaire e Cretin, se a derrota dos nazistas ficasse apenas no âmbito militar, o risco teria sido ver o fracasso nazista reduzido apenas à derrota diante de um exército mais forte, sem que nunca se evocasse o caráter intrinsecamente criminoso das ações dos responsáveis pelo $3^{\circ}$ Reich, como citam os autores:

Ora, o que importava era que não apenas o exército nazista fosse vencido e derrotado, mas que os responsáveis pela Alemanha hitleriana fossem punidos como criminosos, em relação aos princípios. Sairíamos do campo estritamente militar para entrar no da lei. Certamente, a ingenuidade não é conveniente e houve aí evidentemente um aspecto de "processoespetáculo", mas é preciso constatar que os aliados recorriam ao símbolo da justiça além apenas da superioridade das armas. As responsabilidades individuais eram condenadas no lugar apenas do enfrentamento impessoal dos Estados (BAZELAIRE; CRETIN, 2004, p. 43).

Com base na citação, percebe-se que a recusa da impunidade é algo latente a partir do momento em que os crimes contra a humanidade vêm à tona, e Arendt concorda com essa perspectiva citada pelos autores. Embora haja críticas bem sustentadas, é difícil negar a relevância histórica do Tribunal de Nuremberg pela contribuição que trouxe em consolidar o entendimento da responsabilidade individual dos sujeitos não como entes abstratos, mas sim como indivíduos e

\footnotetext{
${ }^{18}$ Segundo Pereira, para Winston Churchill, primeiro-ministro da Grã-Bretanha, o ideal era apelar para uma eliminação rápida: uma execução por pelotão de fuzilamento, que não durasse mais do que seis horas. Com isso, ele esperava evitar um julgamento longo e complexo, para o qual não havia precedentes nem ao menos justificativas legais irrefutáveis. A princípio, o presidente dos EUA, Franklin Delano Roosevelt, aceitou a ideia de Churchill, mas a maioria dos demais políticos americanos, não. Logo, os soviéticos começaram a insistir num julgamento que pudesse expor ao mundo a natureza criminosa do Terceiro Reich. Harry S. Truman, que sucedeu Roosevelt na presidência dos EUA a partir de abril de 1945, concordou. Posteriormente a Inglaterra concordou. PEREIRA, Wagner Pinheiro. O julgamento de Nuremberg e de Eichmann: o cinema como fonte, prova documental e estratégia pedagógica. em: <http://www.dhnet.org.br/direitos/anthist/nuremberg/eichmann_nuremberg_israel.pdf>. Acesso em: 22 dez. 2014 , p. 03. Disponível
} 
sujeitos históricos capazes de responder por seus próprios atos com personalidade jurídica em âmbito internacional, direitos e obrigações.

\section{Considerações finais}

Em 23 de maio de 1949 decidiu-se que a Alemanha deveria iniciar um processo de transição democrática. Sua nova Constituição (ainda em vigor) é denominada Lei Fundamental da República Federal da Alemanha, cujo artigo $3^{\circ}$, parágrafo 3 , sobre a igualdade perante a lei estabelece:

Ninguém poderá ser prejudicado ou favorecido por causa do seu sexo, da sua descendência, da sua raça, do seu idioma, da sua pátria e origem, da sua crença ou das suas convicções religiosas ou políticas. Ninguém poderá ser prejudicado por causa da sua deficiência ${ }^{19}$.

E o artigo $4^{\circ}$ (parágrafos 1 e 2) afirma que:

1 - A liberdade de crença, de consciência e a liberdade de confissão religiosa e ideológica são invioláveis. 2 - É assegurado o livre exercício da religião ${ }^{20}$.

Desde 1949 inúmeros artigos da Constituição alemã reforçam a liberdade para assegurar que a experiência totalitária não se repita, comprometendo-se o Estado alemão a respeitar e proteger a dignidade humana; no caso de o cidadão - seja ele alemão ou estrangeiro - ter os seus direitos ou dados pessoais violados, é possível apelar à justiça. Há também a proteção da dignidade humana e liberdade individual, direitos contra a violação domiciliar e de objeção ao serviço militar, que independem do tipo de personalidade do indivíduo. É uma Constituição que salvaguardou os direitos civis e obteve aceitação plena do povo alemão, que a mantém até hoje.

Em 21.10.2015, a líder alemã Angela Merkel afirmou categoricamente ao presidente de Israel que "a responsabilidade pelo holocausto ou Shoá é da Alemanha"21. Na ocasião, Merkel

\footnotetext{
${ }^{19}$ Constituição da Alemanha. (Lei Fundamental da República Federal da Alemanha). Tradução: Assis Mendonça, Aaschen. Edição impressa, Janeiro de 2011 , p. 18 .

${ }^{20}$ Idem, p. 19.

${ }^{21}$ Merkel reafirmou a culpa alemã dada as declarações do primeiro ministro israelense, Benjamin Netanyahu, em que retirava de Adolf Hitler parte da responsabilidade pelo Holocausto ao atribuí-la ao líder palestino da época, o mufti de Jerusalém Haj Amin al-Husseini (1895-1974). DONCEL, Luis. Merkel: o holocausto foi responsabilidade da Alemanha. Jornal El País. Disponível em: <http://brasil.elpais.com/brasil/2015/10/21 /internacional/1445452767_258305.html>. Acesso em: 22 dez. 2015.
} 
confirmou também que não há motivos para mudar essa visão da História. Foi uma afirmação pública e motivada pelas declarações e interpretações polêmicas feitas pelo presidente israelense sobre o holocausto. Um pouco antes disso, em 18.03.2008, em visita a Israel, Merkel pediu “desculpas pelo holocausto" publicamente entre os dois países. Na ocasião, ela declarou que "os alemães ainda estão cheios de vergonha ${ }^{, 22}$ pelo genocídio praticado contra os judeus.

Ambas as situações referidas demonstram a preocupação e o cuidado da líder do Estado alemão, bem como os impactos e a suposta culpa do passado histórico de seu país, tendo-se em vista que o totalitarismo alemão foi um dos eventos mais marcantes do século $\mathrm{XX}$ e provou que tudo pode ser destruído.

Segundo Arendt, o totalitarismo "traz em si o germe de sua própria destruição" 23 e, embora tenha gerado uma forte crise para a humanidade e uma intensa ruptura em nosso tempo, "corremos o risco de que ele fique conosco de agora em diante" 24 , e com a terrível perspectiva de que se produzam mais lideranças totalitárias entre nós. Sendo assim, compreender a mentalidade totalitária e a culpa alemã no pós $2^{\mathrm{a}}$ Guerra pode contribuir para entendermos alguns dos acontecimentos no mundo atual, como o neonazismo, ou a preferência por parte de alguns grupos pelos regimes ou políticas de extrema direita. Portanto, nosso cuidado ao explorar esse tema não se restringe somente à ideia de um movimento político em si, ou a questões exclusivamente de origens sociais, éticas, filosóficas e étnicas ligadas a essa temática, mas pretende contribuir, a partir de uma dimensão histórica, na compreensão das rupturas morais, violência estatal deliberada, reacionarismos, crimes em massa e guerras, e refletir sobre a culpa e responsabilidade individual dos que operam a máquina pública quando agem contra a sociedade.

Tendo como base o contexto citado, notam-se nos dias atuais resquícios da suposta culpa alemã, principalmente após 18 de outubro de 1945, quando se iniciaram os julgamentos do Tribunal de Nuremberg, em que "ex-nazistas conhecidos sentaram no banco dos réus" 25 e seus crimes passaram a ser amplamente divulgados pelos Aliados. Ao todo, os julgamentos de Nuremberg duraram 285 dias, com divulgação midiática expressiva, que atraiu a atenção do mundo e gerou impactos na própria Alemanha. Foi a primeira vez na História que um tribunal criado pelos

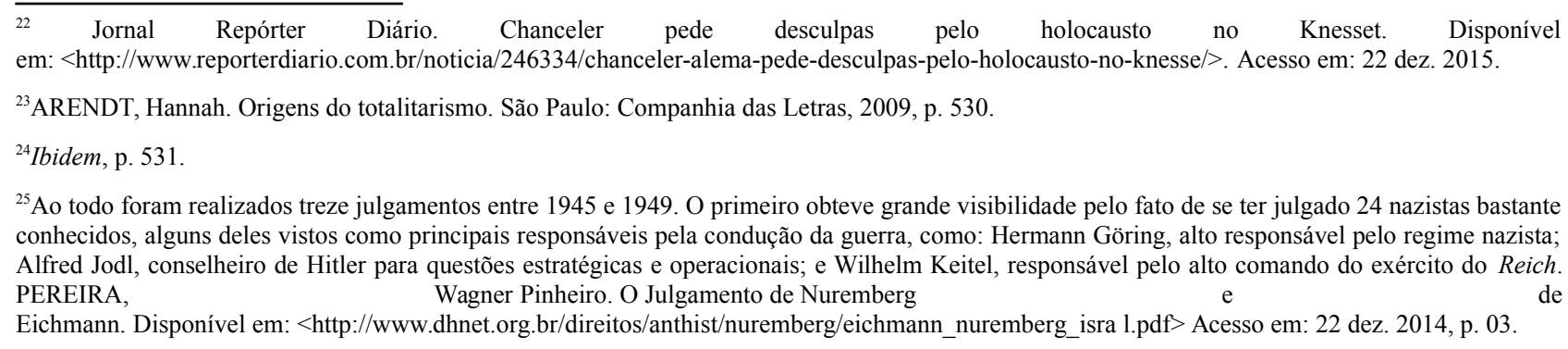


vencedores tinha como objetivo julgar publicamente os vencidos em seu próprio país, razão por que inúmeras críticas são tecidas a ele.

Para Arendt, Nuremberg "era de fato a corte dos vitoriosos e a autoridade de seu julgamento duvidosa, no entanto, eles (vencedores) foram cautelosos na aplicação das penas aos réus alemães"26, pois havia uma suposta percepção de razoabilidade que cuidadosamente se desviava dos indícios de vingança ao mesmo tempo em que se tornava impopular entre os alemães. E no que diz respeito às responsabilidades dos ex-nazistas ao longo dos julgamentos, segundo Arendt, mesmo que estes fossem considerados criminalmente responsáveis pelos seus atos, o Tribunal de Nuremberg foi instituído pelos vencedores para julgar os vencidos. Apesar da crítica contundente sobre o tribunal dos vitoriosos, a autora lhe credita importante contribuição histórica no sentido de cristalizar a "responsabilidade dos sujeitos históricos" que participaram de maneira indireta ou direta dos massacres ocorridos nos tempos de guerra. $\mathrm{O}$ veredicto dos julgamentos do pós $2^{\mathrm{a}}$ Guerra deu-lhe uma "visão mais otimista da natureza humana, pois conseguiu romper com a dita "nova ordem", ilegal e maquiada de legalidade, ao mesmo tempo "horripilante e nova, mas acima de tudo uma ordem" (ARENDT, 2004, p. 104-105) que tinha como parâmetro a conduta "Matarás" (ela se refere ao totalitarismo). Para Arendt, seria inaceitável conceder impunidade aos nazistas que assassinaram milhões de seres humanos:

[...] o nosso senso de justiça acharia intolerável [...] deixar impunes aqueles que assassinaram milhões de seres humanos. Se isso não passasse de um desejo de vingança seria ridículo, sem falar no fato de que a lei e a punição por ela imposta surgiram sobre a terra para quebrar o interminável círculo vicioso da vingança. (ARENDT, 2004, p. 88).

O totalitarismo gerou uma desvalorização geral dos juízos em que se apoiavam os homens do nazismo, pois provocou uma ruptura, transformou tudo que era negativo em algo positivo e supostamente virtuoso, tudo se tornou possível e permitido em nome de um bem maior; mesmo a prática de crimes não era vista como imoral ou criminosa; na ocasião foi aceita e direcionada aos grupos "indesejáveis". Daí a necessidade de ideias como as de Jaspers e Arendt, pois a responsabilidade de tais feitos não se imputa somente às decisões adotadas pelos líderes nazistas daquele momento, tendo em vista que ditaduras implicam cumplicidade ativa ou passiva de uma boa parte de seus próprios cidadãos. Afinal, “difícil era não acreditar que a hipocrisia passou a ser parte do caráter nacional do povo alemão"27, como afirmou Arendt.

\footnotetext{
${ }^{26}$ ARENDT, Hannah. Eichmann em Jerusalém: Um relato sobre a banalidade do mal. São Paulo: Companhia das Letras, 2013, p. 278.

${ }^{27}$ ARENDT, H. Eichmann em Jerusalém: Um relato sobre a banalidade do mal. São Paulo: Companhia das Letras, 2013, p. 65.
} 
Para o historiador Bessel, durante o ano de 1945 os alemães foram transformados de "protagonistas ativos em observadores passivos de seu próprio destino. Um povo que se acostumara a mandar nos outros agora se sentia impotente, sujeito às regras de potências estrangeiras" 28 em seu país. Após a ocupação estrangeira na Alemanha, as atrocidades cometidas pelo regime de Hitler vieram a público e os alemães passaram a ser fortemente hostilizados e violentados em seu próprio território. Nas palavras de Jaspers, se "a penúria da vida cotidiana já era algo extremamente grande" (JASPERS, 1998, p. 129) naquele momento, com a ocupação, a situação piora e se propaga também o seguinte:

Os soldados norte-americanos estavam proibidos de falar conosco, salvo para tratar de assuntos oficiais. Só então foram revelados a todo o povo alemão os crimes do nacionalsocialismo. Eu também, até então, não tinha conhecimento do grau de planejamento e do volume que os crimes haviam alcançado (JASPERS, 1998, p. 130).

Foi nesse contexto que Jaspers optou por enfrentar e reagir ao debate. Ele publicou a obra Die Schuldfrage (A Questão da Culpa), que foi traduzida para o inglês, italiano, sueco, francês, japonês e espanhol. Fora da Alemanha, seu livro foi bastante divulgado, mas obteve pouco êxito naquele país - sua primeira edição publicada em 1946 e esgotou-se somente em 1958. Nota-se que, além de haver pouco interesse pelo livro de Jaspers dentro da Alemanha, houve também “indiferença por parte de alguns dos alemães em investigar criteriosamente os crimes cometidos pelos ex-nazistas" (VOEGELIN, 2009, p. 300), a respeito da shoáh ${ }^{29}$, bem como as responsabilidades e as respectivas culpas das partes envolvidas, como afirmou Voegelin, renomado intelectual alemão que acompanhou a ascensão do nazismo.

Com o intuito de encaminhar para o encerramento desta discussão, segundo o sociólogo Norbert Elias, muitos alemães foram resistentes e "não admitiam" (ELIAS, 1997, p. 340) os ocorridos nos campos de concentração ou preferiam não tomar conhecimento dos fatos, conforme se pode inferir da citação abaixo:

Mais tarde, perguntava-se com frequência: "Mas você deve ter ouvido falar do que estava acontecendo nos campos de concentração, não é verdade?" A resposta era sempre a mesma:

\footnotetext{
${ }^{28}$ BESSEL, Richard. Alemanha, 1945: da guerra à paz. São Paulo: Companhia das Letras, 2010, p. 19.

${ }^{29}$ O termo Shoáh representa literalmente: ruína, destruição, catástrofe e definem o fenômeno de destruição sistemática e socioeconômica, perseguição, expropriação, trabalho forçado, vivência em guetos, tortura e o extermínio de aproximadamente seis milhões de judeus pela política eliminacionista do Partido Nacional Socialista dos Trabalhadores Alemães ou Partido Nazista de Adolf Hitler. Diversitas - Núcleo de Estudos das Diversidades, Intolerâncias e Conflitos da USP. Holocausto e Antissemitismo. Disponível em: < http://diversitas.fflch.usp.br/node/5> Acesso em 30 dez. 2014.
} 
"Eu não sabia". Tentaram o melhor que puderam não perceber qualquer dissabor (ELIAS, 1997 , p. 340, grifos do autor).

Isto quer dizer que mesmo com todas as formas de resistência que tinham como propósito ocultar ou omitir as atrocidades do nazismo, o livro de Jaspers circulava pela Europa, América e Ásia, estimulando fortemente o debate e contribuindo para o não esquecimento da memória, ainda que fosse um assunto polêmico na ocasião; afinal, era o início da cicatrização das feridas da "2a Guerra Mundial, esta última que ofereceu à Europa e principalmente à Alemanha uma era de miséria e desolação" (JUDT, 2014, p. 33).

\section{Referências bibliográficas}

ARENDT, Hannah. A dignidade da política. Rio de Janeiro: Relume Dumará, 2003.

Letras, 2006.

Eichmann em Jerusalém: Um relato sobre a banalidade do mal. São Paulo: Companhia das . Homens em tempos sombrios. São Paulo: Companhia das Letras, 2010.

.Origens do totalitarismo. São Paulo: Companhia das Letras, 2009.

.Responsabilidade e julgamento. São Paulo: Companhia das Letras, 2004.

. JASPERS, Karl. Correspondence, 1926-1969. New York: Harvest Books, 1993.

ASSY, Bethania. Ética, responsabilidade e juízo em Hannah Arendt. São Paulo: Editora Perspectiva, 2015.

AZEVEDO, Antônio Carlos do Amaral. Dicionário de nomes, termos e conceitos históricos. Rio de Janeiro: Nova Fronteira, 1999.

BAZELAIRE, Jean-Paul; CRETIN, Thierry. A justiça penal internacional. São Paulo: Manole, 2004.

BARTOV, Omer (org.). Crimes de guerra: culpa e negação no século XX. Rio de Janeiro: Editora Difel, 2005.

BESSEL, Richard. Alemanha, 1945: Da guerra à paz. São Paulo: Companhia das Letras, 2010.

BESSEL, Richard. Nazismo e guerra. Rio de Janeiro: Objetiva, 2014.

DELACAMPAGNE, Christian. História da filosofia no século XX. Rio de Janeiro: Zahar, 1997.

Constituição da Alemanha. Lei Fundamental da República Federal da Alemanha. Tradução: Assis Mendonça, Aaschen. Edição impressa, Janeiro de 2011. 
ELIAS, Norbert. Os alemães. Rio de Janeiro: Jorge Zahar Editor, 1997.

JASPERS, Karl. A situação espiritual de nosso tempo. Lisboa: Moraes Editores, 1968.

. A bomba atômica e o futuro do homem. Rio de Janeiro: Editora Agir, 1958.

. El problema de la culpa: sobre la responsabilidad política de Alemania. Barcelona:

Ediciones Paidós, 1998.

. Introdução ao pensamento filosófico. São Paulo: Cultrix, 2005.

JUDT, Tony. Pós-guerra: história da Europa desde 1945. Lisboa: Edições 70, 2014.

KITCHEN, Martin. História da Alemanha Moderna: de 1800 aos dias de hoje. São Paulo: Cultrix, 2013.

MEDEIROS, Débora Araujo. Tempos sombrios. São Paulo: Novas Edições Acadêmicas, 2014.

VOEGELIN, Eric. Hitler e os alemães. São Paulo: Realizações Editora, 2009.

\section{DISSERTAÇÕES E TESES}

MEDEIROS, Débora Araujo. Tempos sombrios: Karl Jaspers, Norbert Elias e a culpa alemã. Dissertação (mestrado). UnB - Universidade de Brasília, 2011. Disponível em: $<$ http://repositorio.unb.br/bitstream/10482/10248/1/2011_D\%C3\%A9boraAra

\%C3\%BAjoMedeiros.pdf> Acesso em: 08 jan. 2016.

SERRA, Maria Olilia. Dos tempos sombrios aos cuidados com o mundo: a banalidade do mal e a vida do espírito em Hannah Arendt. Dissertação (mestrado). USPUniversidade de São Paulo, 2014. Disponível em: <http://www.teses.usp.br/teses/disponiveis/8/813 3/tde-15012015-192120/pt-br.php> Acesso em: 12 mar. 2016.

TIZZO, Fabiano. Hannah Arendt: política e responsabilidade no julgamento de Eichmann. Dissertação (mestrado). $\quad$ PUC $\quad-\quad$ SP, $2015 . \quad$ Disponível em: $<$ http://www.sapientia.pucsp.br/tde_busca/arquivo.php?codArquivo=18741> Acesso em: 12 mar. 2016.

\section{ARTIGOS ACADÊMICOS}

MEDEIROS, Débora Araujo. Tempos sombrios: Karl Jaspers e a culpa alemã. Disponível em: $<$ http://periodicos.unb.br/index.php/polemos/article/view/7240/6442> Acesso em: 22 dez. 2015. 
PEREIRA, Wagner Pinheiro. Ojulgamento de Nuremberg e de Eichmann em Jerusalém: o cinema como fonte, prova documental e estratégia pedagógica. Disponível em: <http://www.dhnet.org.br/direitos/anthist/nuremberg/eichmann_nuremberg_israel.pdf $>$ Acesso em: 22 dez. 2014.

GROPPO, Bruno. Reflexões sobre os conceitos de responsabilidade e culpa na obra de Karl Jaspers e sobre sua aplicabilidade à ditadura de 1976-1983 na Argentina. Disponível em: <http://www.seer.ufrgs.br/index.php/anos90/article/view/33387/24254> Acesso em: 12 mar. 2016.

\section{SITES CONSULTADOS}

Diversitas - Núcleo de Estudos das Diversidades, Intolerâncias e Conflitos da USP. Holocausto e Antissemitismo. Disponível em: <http://diversitas.fflch.usp.br/node/5> Acesso em: 30 dez. 2014.

Centro de Estudos Hannah Arendt. Disponível em: <http://www.hannaharendt.org.br/> Acesso em: 20 fev. 2016.

\section{JORNAIS}

DONCEL, Luis. Merkel: o holocausto foi responsabilidade da Alemanha. Jornal El País. Disponível em: $<$ http://brasil.elpais.c om/brasil/2015/10/21/internacional/1445452767_258305.html>. Acesso em: 22 dez. 2015.

DA REDAÇÃO. Chanceler pede desculpas pelo holocausto no Knesset. Jornal Repórter Diário. Disponível em: <http://www.reporterdiario.com.br/noticia/246334/chanceler-alema-pede-desculpaspelo-holocausto-no-knesse/>. Acesso em: $22 \mathrm{dez} .2015$.

TELLES, Sérgio. Arendt e a maior das aventuras, a intelectual. Caderno 2, O Estado de São Paulo, SP, 24 ago. 2013. 